\title{
LIBERALISMO, IDENTIDADE E RECONHECIMENTO EM HABERMAS
}

\author{
Luiz Bernardo Leite Araujo
}

RESUMO - O artigo apresenta a posição ocupada pela teoria discursiva de Jürgen Habermas no debate entre liberalismo e multiculturalismo. Adotando uma perspectiva universalista sensível às diferenças, resultante da tese da relação interna entre democracia e estado constitucional Habermas enfoca três aspectos interligados e diretamente vinculados à questão do reconhecimento: a idéia liberal de igualdade, os direitos de grupos e o igual tratamento das culturas. A defesa da conjugação do ideal igualitário da cidadania democrática com as demandas legítimas de indivíduos e grupos se funda numa abordagem peculiar situada entre o liberalismo cego e o multiculturalismo forte.

PALAVRAS-CHAVE - Igualitarismo. Liberalismo. Multiculturalismo. Reconhecimento.
ABSTRACT - The article presents the position occupied by Jürgen Habermas's discourse theory in the debate between liberalism and multiculturalism. Adopting a difference-sensitive universalistic perspective, resulting from the thesis of the internal relation between democracy and constitutional state, Habermas focuses on three linked aspects that are directly connected with the question of recognition: the liberal idea of equality, group rights, and the equal treatment of cultures. The defense of the connection of the egalitarian ideal of democratic citizenship with the legitimate demands of individual persons and groups is based on a peculiar approach situated between blind liberalism and strong multiculturalism.

KEY WORDS - Egalitarianism. Liberalism. Multiculturalism. Recognition.

Não se conclua que execramos as individualidades únicas, nem que amamos os que são propriamente multicores. É ser temerário; concluamos, antes, que a variedade deleita. (Machado de Assis. Crônica de "A Semana". Gazeta de Notícias, 3 de novembro de 1895).

Na opinião de Will Kymlicka, um de seus principais defensores, o culturalismo liberal tornou-se a posição dominante na filosofia política contemporânea, em cuja literatura já se pode detectar um consenso emergente em virtude da ausência de alternativas. ${ }^{1}$ A despeito de algumas disputas em torno de questões metodológicas e normativas, a visão liberal-culturalista visão segundo a qual certos direitos específicos de grupos étnicos e nacionais devem ser adotados para além do conjunto familiar dos direitos civis e políticos de cidadania protegidos nas democracias

Universidade Estadual do Rio de Janeiro - UERJ/CNPq

Cf. KYMLICKA, W. "Introduction: an emerging consensus?" Ethical Theory and Moral Practice, 1

(1998): p. 143-157 (republicado em: KYMLICKA, W. Politics in the vernacular: nationalism, multiculturalism and citizenship. Oxford: Oxford University Press, 2001, p. 39-48).

\begin{tabular}{|l|l|l|l|l|l|}
\hline VERITAS & Porto Alegre & v. 52 & n. 1 & Março 2007 & p. 120-136 \\
\hline
\end{tabular}


liberais, nas suas formas mais conhecidas de multiculturalismo liberal e nacionalismo liberal, obteve uma vitória tão rápida quanto surpreendente simplesmente porque as possíveis opções do republicanismo e do pós-modernismo não apresentam alternativas claras. Entretanto, à parte a constatação importante de que determinados temas antes ocultos ou reprimidos ganharam, por assim dizer, direito de cidadania na literatura filosófico-política da última década, é duvidoso que se possa considerar o culturalismo liberal a posição dominante, e mais duvidoso ainda que o republicanismo deva ser tido como uma posição superada e mesmo em oposição ao liberalismo. Na opinião de Brian Barry, que adota uma versão nãomarxista de igualitarismo universalista fortemente inspirada na teoria da justiça como eqüidade de John Rawls, a possível convergência da literatura recente nas questões da diferença e do reconhecimento, ou seja, em "visões que apóiam a politização das identidades de grupos, em que a base cultural da identidade comum é reivindicada", ${ }^{2}$ decorreria mais do desinteresse inicial pelo tema do multiculturalismo entre os filósofos do que da inexistência de uma alternativa clara, lacuna que Barry pretende justamente preencher através de um tratamento crítico do problema. Ao contrário do que foi sugerido, a alternativa da cidadania republicana, na qual os cidadãos compartilham um conjunto idêntico de direitos comuns de cidadania iguais direitos jurídicos e políticos, aos quais foram adicionados elementos sociais e econômicos ao longo do século passado, não apenas é clara mas também correta: Kymlicka apenas discorda dela, o que conduz Barry a suspeitar de seu credo liberal. O ponto central do liberalismo é que ele é universalista, tanto quanto o projeto iluminista do qual é um componente fundamental, sendo a teoria rawlsiana a principal manifestação recente dessa concepção de cidadania em todos os seus aspectos, seja o dos iguais direitos civis e políticos (primeiro princípio), seja o do reconhecimento das demandas de cidadania econômica e social (segundo princípio), ${ }^{3}$ tornando-se imprópria a incorporação de direitos culturais.

Embora não seja o foco privilegiado da presente investigação, particularmente devotada à posição ocupada pela teoria discursiva de Jürgen Habermas na querela entre multiculturalismo e liberalismo, ${ }^{4}$ o debate entre o culturalismo liberal de

2 BARRY, B. Culture and Equality: an egalitarian critique of multiculturalism. Cambridge (Mass.): Harvard University Press, 2002, p. 5. O grifo é meu e sua importância reside no fato de que o autor exclui de sua análise os casos em que as identidades de grupo não sejam baseadas em diferença cultural, algo que realmente torna o debate impreciso, na medida em que toda política da diferença ou política do reconhecimento passa a ser interpretada como sinônimo de multiculturalismo. Habermas, como veremos, presta especial atenção à diversidade desses fenômenos.

3 Barry refere-se, evidentemente, aos famosos princípios de justiça estabelecidos por Rawls em A Theory of Justice: o primeiro princípio da "igual liberdade" e o segundo princípio composto de duas partes, a primeira chamada de "princípio da diferença" e a segunda de "princípio da igualdade de oportunidades". A notar a curiosa observação de Barry de que não pretende defender nada do que Rawls escreveu desde cerca de 1975, incluindo as interpretações e revisões da obra original de 1971 (Ff. Ibidem, p. 331, nota 27).

4 Nesse sentido, o presente artigo integra e amplia as reflexões iniciadas no texto intitulado "Habermas e a questão do multiculturalismo", a ser publicado em volume coletivo das Edições Tempo Brasileiro. Para um exame filosófico do tema, cf. FRASER, N. and HONNETH, A. Redistribution or Recognition? A Political-Philosophical Exchange. London: Verso, 2003. Para uma discussão da obra 
Kymlicka e o liberalismo igualitário de Barry ilustra sobremaneira os contornos da discussão e permite enquadrar mais adequadamente a postura de Habermas. Se, por um lado, salta aos olhos uma certa afinidade eletiva entre a teoria habermasiana e a perspectiva universalista dos direitos individuais adotada pelo segundo, não é menos verdade, por outro lado, que o modelo habermasiano de democracia deliberativa opõe-se à cegueira do liberalismo insensível às diferenças culturais, aproximando-se assim do primeiro. Na realidade, o tema do multiculturalismo ocupa a atenção de Habermas, desde o momento em que irrompe na cena principal do debate filosófico-político contemporâneo, e, embora não haja um tratamento sistemático, há certamente uma contribuição significativa, a começar pela análise do próprio termo e também pelo enfoque inovador das questões envolvidas no debate. É notável, nesse sentido, a pronta intervenção habermasiana à contribuição reconhecidamente inaugural da discussão promovida por Charles Taylor em seu ensaio sobre a política do reconhecimento. ${ }^{5}$ Em sua crítica, ${ }^{6}$ o filósofo alemão registra que, embora estejamos diante de fenômenos relacionados com lutas pelo reconhecimento de identidades coletivas, e, portanto, com a defesa comum contra a opressão, a marginalização e o desrespeito a grupos minoritários, primariamente definidos em termos culturais, seja no âmbito de uma cultura majoritária, seja no interior da comunidade dos povos, há diferentes níveis de análise. É necessário, portanto, não apenas distingui-los segundo a especificidade de cada luta pelo reconhecimento, mas também diferenciar os planos discursivos nos quais os debates estão situados, ainda que o alvo principal seja o mesmo sistema de direitos fundado no indivíduo. Dentre esses fenômenos, destacam-se o feminismo, a luta das minorias étnicas e culturais, o nacionalismo e o (neo)colonialismo.

Enquanto a causa feminista pode ser descrita apropriadamente como de reconhecimento de uma interpretação específica baseada em diferenças de gênero, transformando assim a relação entre os sexos e afetando diretamente os papéis masculinos historicamente sedimentados, ${ }^{7}$ a luta das minorias étnicas e culturais

de Barry, cf. KELLY, P. (ed.). Multiculturalism Reconsidered: 'Culture and Equality' and its Critics. Oxford: Polity Press, 2002.

TAYLOR, Ch. "The politics of recognition", in: GUTMANN, A. (ed.). Multiculturalism: examining the politics of recognition. Princeton: Princeton University Press, 1994, p. 25-73. Trata-se de uma edição expandida, incluindo o comentário de Habermas (ver a nota seguinte) à edição alemã da obra original Multiculturalism and the 'Politics of Recognition': An Essay. Princeton: Princeton University Press, 1992. Cabe destacar também, no contexto inaugural do debate sobre o tema, a obra de Iris Young (Justice and the Politics of Difference. Princeton: Princeton University Press, 1990) que declaradamente buscava uma alternativa entre o individualismo atomista e o comunitarismo coletivista através do foco preferencial na diversidade dos grupos étnicos e culturais.

6 HABERMAS, J. "Struggles for Recognition in the Democratic Constitutional State", in: GUTMANN, A. (ed.). Multiculturalism: examining the politics of recognition, op. cit., p. 107-148 (republicado em: HABERMAS, J. The inclusion of the other: studies in political theory. Cambridge (Mass.): The MIT Press, edited by Ciaran Cronin and Pablo De Greiff, 1998, p. 203-236).

Sobre a política feminista, cf. BENHABIB, S. "Multiculturalism and Gendered Citizenship", in: The Claims of Culture: equality and diversity in the global era. Princeton: Princeton University Press, 2002, p. 82-104. Trata-se de uma perspectiva afinada com a teoria discursiva, haja vista a defesa da tese, já no prefácio, segundo a qual "num modelo democrático deliberativo, a sensibilidade à política da cultura e uma posição universalista forte não são incompatíveis", de modo que "a igualdade 
diz respeito ao reconhecimento de tradições e de formas de vida marginalizadas por uma cultura majoritária, cujos membros, em que pese o fato de terem a autocompreensão modificada em alguma medida, não alteram necessariamente seus papéis em razão de uma interpretação revisada das conquistas e interesses dos membros dos grupos minoritários. ${ }^{8}$ Movimentos nacionalistas, por seu turno, visam sobretudo a autodeterminação política de povos que se vêem como grupos homogêneos sob o pano de fundo de um destino histórico comum ${ }^{9}$ e, desse modo, pretendem constituir uma comunidade de destino, ao passo que o anticolonialismo se dirige contra uma ordem internacional baseada na hegemonia da cultura ocidental, ${ }^{10}$ cujos valores particulares se impõem de forma intervencionista em nome da universalidade. Por mais vinculados que estejam uns aos outros, tais fenômenos não podem ser confundidos, sob pena de obscurecer a complexidade de uma realidade marcada pela multiplicidade no interior da própria diversidade. $\mathrm{O}$ caso do Québec, por exemplo, sempre lembrado na literatura multiculturalista, é ilustrativo dessa complexidade, devendo ser situado, a juízo de Habermas, na fronteira entre o segundo e o terceiro casos, na medida em que a aspiração da minoria francófona canadense, à parte tendências separatistas de parcela da população, é a de tornar-se um Estado dentro de um Estado, constituindo-se, assim, na outra ponta do enlace federativo, em maioria cultural em face de outras minorias domésticas.

Quanto aos diferentes níveis de análise desses fenômenos variados, Habermas distingue os discursos político, filosófico e jurídico, demonstrando particular interesse pelo último aspecto do problema. No primeiro nível, com efeito, a querela sobre o reconhecimento parece renovar o debate sobre a modernidade que havia sido interpretado por Habermas sob o signo de um projeto inacabado, ${ }^{11}$ opondo

democrática e as práticas deliberativas são totalmente compatíveis com a experimentação cultural e com novos modelos jurídicos e institucionais que acomodem o pluralismo cultural".

8 Para o enfoque em minorias nacionais, cujos membros pertencem a nações incorporadas a Estados multinacionais, através de processos involuntários de conquista e de colonização ou da formação voluntária de uma federação, por um lado, e em grupos étnicos, cujos membros emigram individual ou coletivamente de várias nações, dando origem a Estados poliétnicos, por outro lado, vide: KYMLICKA, W. Multicultural Citizenship: a liberal theory of minority rights. Oxford: Clarendon Press, 1995. É nessa obra que Kymlicka estabelece as bases principais do mencionado culturalismo liberal, segundo o qual determinadas medidas em prol de grupos específicos são requeridas, em nome da justiça étnico-cultural, embora "proteções externas" visando reduzir a vulnerabilidade dos grupos frente ao poder econômico e político da maioria e "restrições internas" visando reforçar a solidariedade no interior de grupos devam estar submetidas a princípios liberais básicos a fim de promover relações de igualdade entre os grupos e proteger a liberdade dos indivíduos dentro dos grupos.

9 Quanto à questão do nacionalismo, cf. TAMIR, Y. Liberal Nationalism. Princeton: Princeton University Press, 1993; MILLER, D. On Nationality. Oxford: Oxford University Press, 1995; GANS, C. The Limits of Nationalism. Cambridge: Cambridge University Press, 2003.

${ }^{10}$ Em relação à justiça global e temas correlatos, cf. HELD, D. Democracy and the Global Order: from the modern state to cosmopolitan governance. London: Polity Press, 1995; RAWLS, J. The Law of Peoples; with 'The idea of public reason revisited'. Cambridge (Mass.): Harvard University Press, 1999; CRONIN, C. and DE GREIFF, P. (Eds.). Global Justice and Transnational Politics: essays on the moral and political challenges of globalization. Cambridge (Mass.): The MIT Press, 2002.

11 Cf. HABERMAS, J. Der philosophische Diskurs der Moderne. Frankfurt: Suhrkamp, 1985 [O discurso filosófico da modernidade. Lisboa: Dom Quixote, trad. de A. Marques et alii, 1990]. Nesse tópico, há 
agora o radicalismo pós-moderno ao tradicionalismo pré-moderno na nova configuração do "politicamente correto", que pouco contribui para a compreensão da questão e ainda menos para sua solução política. No plano filosófico, o que está em jogo é a compreensão intercultural, cujas dificuldades aparecem claramente em todos aqueles fenômenos associados ao multiculturalismo, os quais reintroduzem o tema clássico da racionalidade e suas pretensões de universalidade, ${ }^{12}$ tanto cognitivas quanto normativas, na relação entre sociedade global unificada e sociedades locais fragmentadas, movendo-se entre o holismo e o contextualismo. Do ponto de vista jurídico, a discussão fundamental trazida pelo multiculturalismo reside na interpretação do Estado democrático de direito, reveladora da tensão entre o princípio do igual tratamento das pessoas e a busca de proteção de suas identidades culturais, em torno da qual Habermas reitera suas reservas em face do liberalismo clássico, não lhe-opondo uma leitura comunitarista como a de Taylor, que adota a falsa pista da oposição entre uma política de universalização dos direitos individuais e uma política de consideração pelas diferenças culturais, ${ }^{13}$ mas sim corrigindo uma compreensão inapropriada dos princípios liberais, a fim de demonstrar que o sistema de direitos, corretamente entendido, "não é cego às diferenças culturais" e não precisa ser contrastado com "um modelo que introduz uma noção de direitos coletivos estranha ao sistema". ${ }^{14}$

Em ambas as passagens, Habermas se refere aos dois tipos de liberalismo procedimental e substancial distinguidos por Taylor, ou, na nomenclatura de Michael Walzer, liberalismo 1 e liberalismo 2, advertindo que não se trata de uma simples correção da política da igual dignidade pela política da diferença, mas de um ataque ao núcleo individualista da concepção moderna de liberdade. Em sua análise, com efeito, Taylor distingue os ideais de dignidade e de autenticidade em torno dos quais forjou-se a identidade moderna, cada um dos quais remetendo a um princípio norteador de caráter universalista, porém radicalmente diferentes um de outro. De um lado, o da igual cidadania fundada em direitos compartilhados por todos os indivíduos. De outro lado, o do reconhecimento das pessoas e dos grupos em sua profunda alteridade. Evidentemente, o filósofo canadense é consciente do fato de que, no primeiro caso, trata-se de uma potencialidade humana

concordância, ainda que por razões distintas, entre os autores até aqui mencionados sobre a pouca serventia das versões desconstrucionistas da política da diferença para lidar com os problemas teóricos e práticos de sociedades modernas marcadas por um pluralismo cultural intenso e permanente.

12 Sobre o assunto, cf. HABERMAS, J. Nachmetaphysisches Denken. Frankfurt: Suhrkamp, 1988 [Pensamento pós-metafísico. Rio de Janeiro: Tempo Brasileiro, trad. de Flávio Siebeneichler, 1990], sobretudo os Capítulos 3 ("Motivos de pensamento pós-metafísico", p. 37-61) e 8 ("A unidade da razão na multiplicidade de suas vozes", p. 151-182), e também, do mesmo autor: Erläuterungen zur Diskursethik. Frankfurt: Suhrkamp, 1991

13 O termo "comunitarismo" é utlizado aqui em sentido restrito, dizendo respeito a uma forte impregnação ética da política e do direito e não a uma atitude de rejeição da modernidade em sua totalidade, que não se aplica certamente à análise tayloriana. Cf. TAYLOR, C. Sources of the Self: the making of the modern identity. Cambridge (Mass.): Harvard University Press, 1989 [As Fontes do Self: a construção da identidade moderna. S. Paulo: Loyola, 1997].

14 HABERMAS, J. "Struggles for Recognition in the Democratic Constitutional State", in: The inclusion of the other: studies in political theory, p. 207 e p. 210. 
generalizável, baseada na mesma capacidade de agir de acordo com princípios morais aceitáveis por todos os agentes racionais, enquanto que, no segundo caso, apesar de tratar-se igualmente de um potencial humano universal, que é o de formar e definir a própria identidade como indivíduo e também como membro de uma cultura, o princípio do igual respeito pelas pessoas dirige-se a uma particularidade. Contudo, é exatamente pela referência a uma característica universal, ainda que distinta, que há exigência de reconhecimento por aquilo que resulta do potencial humano, de modo que a negação do igual respeito às culturas infringe o princípio fundamental da igualdade. Como diz Taylor, ao denunciar o primeiro modelo de liberalismo inóspito às diferenças por sua aplicação uniformizadora de regras e sua suspeita em relação a metas coletivas, a forte demanda por um igual respeito a todas as culturas funda-se na premissa de que "reconhecimento forja identidade", de forma que "todos deveriam desfrutar da suposição de que sua cultura tradicional tem valor". ${ }^{15}$ Taylor fala em suposição ou ainda em hipótese inicial de igual valor das culturas, consciente do problema do nivelamento às avessas, isto é, de que a política do reconhecimento pode acabar tornando tudo idêntico, mantendo entretanto a tese central, criticada por Habermas, da divergência entre as políticas do universalismo e da diferença no seio do liberalismo.

Torna-se importante, nesse ponto, recordar alguns elementos estabelecidos por Habermas em sua compreensão democrático-procedimental dos direitos, ${ }^{16}$ a qual determina sua posição no debate sobre o multiculturalismo. Com efeito, sua afirmação de que o sistema de direitos não é cego às diferenças culturais, e tampouco a condições sociais desiguais, depende integralmente de uma tese fundamental adotada pela teoria discursiva, a saber, a tese da relação interna, portanto não-contingente, entre Estado de direito e democracia, para cuja demonstração é necessário, nas palavras de Habermas, "o esclarecimento das seguintes proposições: o direito positivo não pode ser submetido simplesmente à moral; a soberania do povo e os direitos humanos pressupõem-se mutuamente; o princípio da democracia possui raízes próprias, independentes da moral" ${ }^{17}$ Cabe destacar o fato de que o esclarecimento dessas proposições é o que permite a Habermas apontar o equívoco da oposição construída por Taylor entre a política universalista da igual

15 TAYLOR, Ch. "The politics of recognition", in: GUTMANN, A. (ed.). Multiculturalism: examining the politics of recognition, p. 66 e p. 68.

16 Refiro-me ao mais importante tratado habermasiano em filosofia política e do direito (ao qual está diretamente vinculada a obra de teoria política já citada, publicada quatro anos depois): HABERMAS, J. Faktizität und Geltung. Beiträge zur Diskurstheorie des Rechts und des demokratischen Rechtsstaats. Frankfurt: Suhrkamp, 1992 [Direito e Democracia: entre facticidade e validade. Rio de Janeiro: Tempo Brasileiro, 2 vols., trad. de Flávio Siebeneichler, 1997]. Para a exposição que se segue, utilizo livremente algumas passagens do ensaio "Moral, Direito e Política - Sobre a Teoria do Discurso de Habermas", in: AGUIAR, O.; OLIVEIRA, M.; SAHD, L. F. (eds.). Filosofia política contemporânea. Petrópolis: Vozes, 2002, p. 214-235. Ver também os excelentes estudos reunidos em: WHITE, S. K. (ed.). The Cambridge Companion to Habermas. Cambridge: Cambridge University Press, 1995.

17 HABERMAS, J. Direito e Democracia: entre facticidade e validade, Vol. 2, p. 310. A citação é extraída do Posfácio de 1994, que resume exemplarmente, a meu ver, o núcleo da argumentação habermasiana. 
dignidade de todos os cidadãos e a política do reconhecimento das identidades de indivíduos e grupos, a qual é baseada numa interpretação paternalista do sistema de direitos que ignora a conexão interna entre autonomia privada e autonomia pública. Trata-se, pois, de antepor a uma leitura seletiva do liberalismo moderno uma interpretação que resgate a inter-relação de duas intuições normativas fundamentais que satisfazem o critério moral do universalismo igualitário, que exige o respeito igual por todos, e o critério ético do individualismo, segundo o qual cada pessoa tem o direito de conduzir sua vida de acordo com suas próprias preferências e convicções.

Tal relação interna é apreendida com base na releitura de duas interpretações contrárias e conflitantes na filosofia política, representadas pelo liberalismo clássico e pelo republicanismo cívico. Na tradição liberal, que remonta a Locke, a ênfase é posta no caráter impessoal das leis e na proteção das liberdades individuais, de tal modo que o processo democrático é compelido por (e está ao serviço dos) direitos individuais que garantem a cada pessoa a liberdade de buscar sua própria realização. Cristalizou-se aqui uma visão individualista e instrumentalista do papel dos cidadãos. A cidadania é concebida com base no modelo de uma pertença organizacional capaz de fundamentar uma posição jurídica, ou seja, os indivíduos permanecem exteriores ao Estado, contribuindo, de certa forma, para a sua reprodução, através de eleições e pagamento de impostos, a fim de conseguir em troca benefícios organizacionais. Na tradição republicana, que remonta a Rousseau, a primazia é atribuída ao processo democrático enquanto tal, entendido como uma deliberação coletiva que impele os cidadãos à busca de um entendimento sobre 0 bem comum. Nessa visão, a liberdade humana tem sua máxima expressão, não na busca de preferências privadas e sim na autolegislação mediante a participação política. A cidadania é vista através do modelo da pertença a uma comunidade ético-cultural, que se determina a si mesma, ou seja, os indivíduos estão integrados na comunidade política como partes num todo, de tal maneira que, para formar sua identidade pessoal e social, necessitam do horizonte de tradições comuns e de instituições políticas reconhecidas. ${ }^{18}$

Segundo Habermas, as divergências não são inteiramente surpreendentes, se levarmos em conta o fato de que o pensamento democrático moderno forjou-se em meio a um conflito interno entre duas noções radicalmente distintas de liberdade, exemplarmente comparadas por Benjamin Constant sob os títulos de liberdade dos "modernos" e liberdade dos "antigos". ${ }^{19}$ A tradição liberal atribui maior peso à primeira, sobretudo à liberdade de consciência e de pensamento, ao passo que a tradição republicana dá maior importância à segunda, particularmente às chama-

18 Sobre esses dois conceitos concorrentes de cidadania, vide os seguintes ensaios, respectivamente de 1988 e 1990, retomados em Direito e Democracia: entre facticidade e validade (Vol. 2): "A soberania do povo como processo" (p. 249-278) e "Cidadania e Identidade Nacional" (p. 279-305). Cf. tb. "On the relation between the nation, the rule of law and democracy", in: The inclusion of the other: studies in political theory, p. 129-153.

19 Cf. CONSTANT, B. "De la liberté des anciens comparée à celle des modernes", in: De l'esprit de conquête et de l'usurpation. Paris: Flammarion, 1986, p. 265-291 [A edição original é de 1819]. 
das liberdades políticas iguais. Sendo assim, ambas concorrem a partir de concepções unilaterais que concebem, por um lado, os "direitos humanos" como expressão da autodeterminação moral, e, por outro lado, a "soberania popular" como expressão da auto-realização ética. De acordo com a interpretação liberal, os cidadãos não se distinguem essencialmente das pessoas privadas que fazem valer seus interesses pré-políticos contra o aparelho estatal, e por isso a prioridade recai sobre as liberdades negativas que asseguram o exercício da autonomia individual. Segundo a interpretação republicana, a cidadania se atualiza somente na prática de autodeterminação coletiva, razão pela qual o primado incide sobre a autonomia política dos cidadãos, que constitui um fim em si mesmo e que ninguém pode realizar perseguindo privadamente interesses próprios, pois pressupõe o caminho comum de uma prática intersubjetiva. Assim, o liberalismo e o republicanismo tendem a ressaltar apenas um dos aspectos da autonomia dos indivíduos como base da legitimidade democrática. Ao defender uma relação interna entre autonomia privada e autonomia pública, a Teoria do Discurso pretende fazer justiça a ambas as tradições, isto é, proporcionar uma justificação do Estado de direito democrático, na qual direitos humanos e soberania popular desempenham papéis distintos, irredutíveis, porém complementares.

É de tal justificação que provém o modelo procedimental da teoria discursiva da moral e da política, uma vez que, para demonstrar a tese de uma relação interna entre democracia e estado constitucional, é necessário introduzir um princípio de validação imparcial de normas, conceitualmente anterior à própria distinção entre a moral e o direito, cuja formulação é a seguinte: "São validas as normas de ação às quais todos os possíveis atingidos poderiam dar o seu assentimento, na qualidade de participantes de discursos racionais". ${ }^{20} \mathrm{O}$ princípio do discurso (D) permite evitar tanto uma interpretação moralizante do direito quanto seu confinamento em afirmações comunitárias de valores compartilhados, apontando para um modelo de legitimação que solda a cisão liberal-republicana. Em face do problema de integração das sociedades modernas pluralizadas e secularizadas, nas quais as ordens normativas devem ser mantidas sem as garantias meta-sociais de natureza religiosa ou metafísica, Habermas adota uma compreensão procedimental da razão prática, em cujo cerne está a expectativa da qualidade racional dos resultados obtidos através da ampla e livre discussão entre os participantes de processos argumentativos fundados no princípio do discurso. Enquanto princípio de justificação imparcial das normas de ação em geral, o princípio do discurso (D) está igualmente na base da moralidade e do direito. E é graças a uma diferenciação de usos da razão prática ${ }^{21}$ que Habermas insiste no delineamento sutil entre tal princípio, que explicita o sentido da imparcialidade de juízos práticos, e sua especifi-

HABERMAS, J. Direito e Democracia: entre facticidade e validade, Vol. 1, p. 142.

Na esteira de Kant, Habermas distingue as dimensões ética, pragmática e moral da razão prática. As questões éticas dizem respeito àquilo que é bom para mim ou para nós, ao passo que as questões pragmáticas se referem a meios apropriados para determinados fins práticos. As questões morais, por seu turno, têm a ver com aquilo que é valido para todos, na acepção kantiana de um dever universal. Vide, em particular: HABERMAS, J. Erläuterungen zur Diskursethik,p. 100-118. 
cação como princípio moral (U) segundo o qual "toda norma válida deve satisfazer a condição de que as conseqüências e efeitos colaterais, que (previsivelmente) resultarem para a satisfação dos interesses de cada um dos indivíduos do fato de ser ela universalmente seguida, possam ser aceitos por todos os concernidos" ${ }^{\prime 22}$ ou como princípio da democracia (De) de acordo com o qual "somente podem pretender validade legítima as leis jurídicas capazes de encontrar o assentimento de todos os parceiros do direito, num processo jurídico de normatização discursiva" ${ }^{23}$ A nova formulação do princípio do discurso (D) possui dupla vantagem, oriunda de seu alto grau de abstração, em relação àquela originalmente apresentada por Habermas. ${ }^{24}$ Em primeiro lugar, as normas de ação às quais ela se refere não prejulgam o contexto em que estão inseridas, cabendo ao princípio da democracia (De) a especificação como normas que manifestam as propriedades formais das normas jurídicas. Em segundo lugar, os discursos racionais envolvem variadas formas de argumentação que estão abertas a contribuições e informações relacionadas a temas morais, ético-políticos e pragmáticos, incumbindo ao princípio moral (U) a restrição do amplo espectro de questionamentos para o tipo de discurso no qual apenas argumentos morais são decisivos.

Embora distintos, os princípios da moral e da democracia não estão ordenados hierarquicamente. Para Habermas, ao contrário, eles são complementares, de tal modo que a legitimidade jurídica não pode ser assimilada à validade moral, como no caso do jusnaturalismo, e tampouco o direito deve estar completamente separado da moral, como defende o positivismo. O direito é compreendido como um complemento funcional da moralidade pós-tradicional, compensando, assim, vários de seus déficits, tais como os da indeterminação cognitiva e da incerteza motivacional. Além disso, Habermas defende que o princípio da democracia não está subordinado a um sistema de direitos, e sim que eles se constituem de modo co-originário, explicando-se reciprocramente. "Por isso", afirma o autor, "o princípio da democracia só pode aparecer como núcleo de um sistema de direitos" ${ }^{25} \mathrm{~A}$ idéia básica é que o sistema de direitos pode ser desenvolvido a partir da interligação entre o princípio do discurso e a forma jurídica, processo a que Habermas dá o nome de "gênese lógica dos direitos". Tal sistema de direitos, reconhecido por cidadãos que desejam regular a vida em comum por meio do direito positivo,

22 HABERMAS, J. Consciência moral e agir comunicativo. Rio de Janeiro: Tempo Brasileiro, trad. de Guido A. de Almeida, 1989, p. 86 [Moralbewusstsein und kommunikatives Handeln. Frankfurt: Suhrkamp, 1983].

${ }^{23}$ HABERMAS, J. Direito e Democracia: entre facticidade e validade, Vol. 1, p. 145.

${ }^{24}$ Na obra Consciência moral e agir comunicativo, de 1983, Habermas havia formulado da seguinte maneira o princípio D: "Só podem reclamar validez as normas que encontrem (ou possam encontrar) o assentimento de todos os concernidos enquanto participantes de um Discurso prático" (p. 116). Ao falar agora em "normas de ação" em geral, sem expressar um sentido específico de validade normativa, e em "discursos racionais", que podem comportar justificações discursivas de caráter moral, ético e pragmático, Habermas considera que há um espaço amplo para a dedução dos principios da moral e da democracia, por meio de especificações adequadas, a partir do princípio discursivo.

25 HABERMAS, J. Direito e Democracia: entre facticidade e validade, Vol. 1, p. 158. 
delineia as condições gerais necessárias para a institucionalização de processos democráticos de discussão, no âmbito do direito e da política. Habermas aponta cinco categorias básicas de direitos, que incluem direitos à maior medida possível de iguais liberdades subjetivas de ação, ao status de membro na comunidade política, à proteção jurídica individual, ao exercício da autonomia política e a condições básicas de vida que possam garantir a oportunidade de exercer as outras categorias de direitos elencados. "Quando introduzimos o sistema dos direitos desta maneira", conclui Habermas, "torna-se compreensível a interligação entre soberania do povo e direitos humanos, portanto a co-originariedade da autonomia política e da privada. Com isso não se reduz o espaço da autonomia política dos cidadãos através de direitos naturais ou morais, que apenas esperam para ser colocados em vigor, nem se instrumentaliza simplesmente a autonomia privada dos indivíduos para fins de uma legislação soberana. Nada vem antes da prática de autodeterminação dos cidadãos, a não ser, de um lado, o princípio do discurso, que está inserido nas condições de socialização comunicativa em geral, e, de outro lado o medium do direito" . ${ }^{26}$ Como se pode notar, a questão central da legitimidade é abordada através da racionalidade própria do direito moderno, assegurada pelo vínculo entre a autonomia privada e a autonomia pública de cidadãos integrados socialmente através do agir comunicativo. ${ }^{27}$

O modelo habermasiano de democracia "procedimental" termo que serve para designar a tentativa de realização dos direitos vinculados às duas formas de autonomia dos cidadãos pela incorporação de discursos pragmáticos, ético-políticos e morais em marcos institucionais, é introduzido também pelo contraste entre as alternativas clássicas republicana e liberal. Como o modelo republicano, rejeita-se a visão do processo político como sendo, primariamente, o da competição entre preferências privadas. Como o modelo liberal, entretanto, considera-se a visão de uma cidadania unificada e ativamente motivada por uma concepção compartilhada do mundo como irrealista nas sociedades modernas pluralistas. Tais modelos procedem, na verdade, de um mesmo conceito de sociedade centrada no Estado, embora este último seja tido, num caso, como o protetor de uma sociedade econômica, e, no outro caso, como a institucionalização de uma comunidade ética. $\mathrm{Na}$ visão liberal, a constituição do Estado de direito é o aspecto capital para o equilíbrio dos interesses de sujeitos privados que buscam a satisfação de suas expectativas concorrentes. Na visão republicana, a formação de uma comunidade ético-política estruturada é o elemento central para a autodeterminação democrática de sujeitos vinculados na totalidade coletiva. A primeira perspectiva prescinde da idéia de cidadania e do papel constitutivo da formação política da opinião e da vontade, ao passo que a segunda menoscaba as fronteiras entre Estado e sociedade civil, através da excessiva politização de uma esfera pública voltada contra a administração burocrática.

${ }^{26}$ Idem, Ibidem, p. 164-165

Para uma exposição sucinta da teoria política habermasiana, cf. "On the internal relation between the rule of law and democracy", in: The inclusion of the other: studies in political theory, p. 253-264. 
Ambos os elementos da normatização constitucional e do processo político de formação da opinião e da vontade são assumidos sob nova composição, na teoria discursiva da democracia: "Para ela processos e pressupostos comunicativos da formação democrática da opinião e da vontade funcionam como a comporta mais importante para a racionalização discursiva das decisões de um governo e de uma administração vinculados ao direito e à lei" ${ }^{28}$ Habermas sugere um processo em dois trilhos, no qual há uma divisão de trabalho entre o "público fraco" a esfera pública informalmente organizada, que abrange as associações privadas, instituições culturais, grupos de interesse com preocupações públicas, Igrejas, instituições de caridade, etc. e o "público forte" as corporações parlamentares e outras instituições formalmente organizadas do sistema político. A soberania popular, interpretada de modo intersubjetivista, não se concentra em um ator coletivo que reflete a totalidade e age em função dela, como no modelo republicano, nem é banida para o anonimato de competências jurídico-constitucionais, como no modelo liberal, mas faz-se valer como poder produzido comunicativamente. Nesse sentido, os discursos institucionalizados para a formação política da opinião e da vontade são vitais para o exercício da cidadania, na medida em que o processo democrático impele os participantes ao engajamento em perspectivas recíprocas e à busca de interesses generalizáveis. O cerne de uma compreensão genuinamente procedimental da democracia, nos termos de Habermas, "consiste precisamente no fato de que o processo democrático institucionaliza discursos e negociações, com o auxílio de formas de comunicação que devem fundamentar a suposição da racionalidade para todos os resultados obtidos conforme o processo", sendo seu núcleo dogmático, no sentido de algo que não podemos eludir, "a idéia de autonomia, segundo a qual os homens agem como sujeitos livres, na medida em que obedecem às leis que eles mesmos estabeleceram, servindo-se de noções adquiridas num processo intersubjetivo". ${ }^{29}$

A posição de Habermas no debate em torno do multiculturalismo, como já salientado, é determinada pela compreensão democrático-procedimental dos direitos que tentamos apresentar em suas linhas gerais. Trata-se de uma posição peculiar, uma vez que permite ao autor endossar determinadas políticas da diferença que contribuam decisivamente para a inclusão dos cidadãos aos quais é negado o pleno reconhecimento como membros de uma comunidade política e, ao mesmo tempo, chamar a atenção para potenciais ameaças à autonomia individual associadas às demandas específicas de grupos, particularmente no que tange aos chamados direitos culturais. Desse modo, como em muitos outros temas tratados no âmbito da teoria discursiva, a postura de Habermas se caracteriza pelo difícil equilíbrio entre igualdade e diversidade, advogando, como antes ressaltado em sua crítica a Taylor, uma concepção universalista sensível às diferenças nos recen-

HABERMAS, J. Direito e Democracia: entre facticidade e validade, Vol. 2, p. 23.

Idem, Ibidem, p. 27 e p. 190. Para uma breve apresentação do modelo habermasiano de democracia, cf. "Three normative models of democracy", in: The inclusion of the other: studies in political theory, p. 239-252 
tes debates multiculturais. Entretanto, há dúvida sobre a superioridade de sua abordagem comparada com as alternativas do liberalismo e do republicanismo, tais como apresentadas pelo pensador alemão ${ }^{30}$ para lidar com diferenças politicamente significativas entre grupos étnicos, nacionais e religiosos. ${ }^{31}$ Nesse viés, não são poucas as críticas ao modo discursivo de tratamento da questão, seja porque subestimaria a importância das identidades culturais, seja por não estar suficientemente atento à relevância da cultura no campo da política, seja ainda em razão de não reconhecer a profundidade da diversidade e dos conflitos de valores nas sociedades pluralistas contemporâneas. ${ }^{32}$ Em breves palavras, o desafio parece residir na comprovação de que o tipo de normatividade subjacente à interpretação democrático-procedimental do liberalismo político permite conjugar de modo satisfatório o ideal igualitário da cidadania democrática com as demandas legítimas de indivíduos e grupos aos quais as normas, embora justificadas do ponto de vista dos interesses de todos, impõem restrições diferenciadas.

O desafio é enfrentado por Habermas, ao enfocar três aspectos interligados e diretamente vinculados à questão do reconhecimento: a idéia liberal de igualdade, os direitos de grupos e o igual tratamento das culturas. No primeiro caso, o objetivo é a defesa do princípio da igualdade cívica contra as tentativas de desconstrução do liberalismo. No segundo caso, trata-se de apontar as conseqüências ambivalentes dos direitos de grupos fundados pelo multiculturalismo, os quais normalmente produzem o que Habermas chama de uma transformação dialética da igualdade em repressão. No terceiro caso, examina-se a consistência conceitual da interseção de liberdade e igualdade, em casos de igual tratamento das culturas,

${ }^{30}$ O destaque é importante, pois a apresentação feita por Habermas das duas interpretações contrárias e conflitantes na filosofia política possui valor heurístico e, nessa medida, destaca as características principais de forma estilizada. É notório, por exemplo, o teor "comunitarista" desse republicanismo contrastado com o liberalismo, o que pode ser confirmado em seu artigo: "Multiculturalism and the Liberal State". Stanford Law Review, 47, May 1995. Sabe-se, entretanto, que nem o liberalismo e nem o republicanismo constituem tradicõos políticas homogêneas, a ponto de muitos de seus representantes serem enquadrados em ambas, dependendo dos aspectos salientados. O liberalismo político rawlsiano e a teoria discursiva habermasiana são, no meu entender, exemplos notáveis de tal ambivalência (cf. ARAUJO, L. B. L. "A prioridade do justo sobre o bem no liberalismo político e na teoria discursiva", in: OLIVEIRA, N.; SOUZA, D. G. (eds.). Justiça e Política: homenagem a Otfried Höffe. Porto Alegre: EDIPUCRS, p. 29-45). Acerca da leitura habermasiana do republicanismo, cf. BERTEN, A. "Républicanisme et motivation politique", in: MERLE, J. C.; SCHUMACKER, B. (eds.). Figures du communautarisme. Paris: Ophrys, 2001.

31 A dúvida é lançada na própria introdução, de resto muito instrutiva, feita por Cronin e De Greiff para a obra The inclusion of the other. De fato, os editores afirmam que "as teorias altamente abstratas dos direitos humanos e da soberania popular nas quais ele propõe fundar a democracia, tanto no nível nacional quanto no nível supranacional parecem ignorar os valores culturais que moldam as identidades de grupos" [ 'Editor's Introduction', p. vii-xxxii, aqui, p. xxviii], sem deixarem de notar a força e a originalidade de Habermas ao tratar de uma ampla gama de questões no quadro de uma filosofia política singular.

32 Sem intento exaustivo, cabe citar: YOUNG, I. "Communication and the Other: Beyond Deliberative Democracy", in: BENHABIB, S. (ed.). Democracy and difference: contesting the boundaries of the political. Princeton: Princeton University Press, 1996, p. 120-135; BAUMEISTER, A. "Habermas: Discourse and Cultural Diversity". Political Studies, 51 (2003): 740-758. THOMASSEN, L. "The Inclusion of the Other? Habermas and the Paradox of Tolerance". Political Theory, 34 (2006): 439-462. 
problema que tem a ver justamente com a razoabilidade normativa dos custos que indivíduos e grupos devem pagar para uma adaptação à modernização cultural e social. ${ }^{33}$ Tais aspectos, brevemente tratados a seguir, reforçam alguns tópicos da abordagem habermasiana acerca do multiculturalismo, destacando-se sobretudo as seguintes teses: (i) apenas um universalismo igualitário sensível às diferenças pode preencher os requisitos indispensáveis para a proteção da integridade vulnerável de indivíduos com histórias de vida distintas; (ii) embora a implementação dos chamados direitos culturais para membros de grupos discriminados, de modo semelhante aos direitos sociais, siga um desenvolvimento jurídico governado pelo princípio da igualdade cívica, é fundamental que tal expansão do conceito clássico de cidadania não viole direitos individuais, em nome de direitos coletivos, os quais, não sendo suspeitos per se, no entender de Habermas, são legítimos, na medida em que derivam dos direitos culturais do membro individual do grupo; (iii) não apenas as normas, mas também as restrições assimétricas delas decorrentes, aceitas em bases normativas, são uma expressão do princípio de igualdade cívica que norteia o uso público da razão.

Em relação ao primeiro aspecto, trata-se de uma objeção inspirada numa crítica da razão que pretende demonstrar a natureza autocontraditória do conceito de igualdade política, o qual inevitavelmente fracassa perante a relação paradoxal entre o igual tratamento e a realização da justiça nos casos individuais, como poderia ser ilustrado pela concepção modular do consenso sobreposto de Rawls. ${ }^{34}$ De acordo com a crítica desconstrucionista, o problema não reside tanto na formulação de um liberalismo estritamente político, que evita apoiar-se nas doutrinas morais, filosóficas e religiosas as quais compõem uma sociedade democrática, já que a busca da justiça com base no igual tratamento de todos os cidadãos, representa uma idéia básica de qualquer programa liberal, e sim na necessária marginalização das concepções de bem-viver que não compartilham a visão substantiva e particular da vida correta expressa no próprio princípio da igual liberdade, de maneira que o estabelecimento da justiça está fadado ao insucesso por razões conceptuais. O que está em jogo, evidentemente, é o problema da neutralidade de uma ordem política justa em relação às doutrinas abrangentes, frente ao qual Rawls distingue ciosamente dois sentidos: o da neutralidade de "objetivo" ou

${ }^{33}$ Cf. HABERMAS, J. "Equal Treatment of Cultures and the Limits of Postmodern Liberalism". The Journal of Political Philosophy, 13 (2005): 1-28. Esses três aspectos permitem a Habermas retomar, cerca de dez anos após os comentários à política do reconhecimento de Charles Taylor, o tema do multiculturalismo na ocasião de uma crítica à leitura pós-moderna do liberalismo, recentemente em voga e promovida especialmente por Christoph Menke, cuja bibliografia pode ser encontrada ao longo das duas primeiras secões do artigo de Habermas. Vide, entre um e outro, os seguintes artigos: "Remarks on Legitimation Through Human Rights". The Modern Schoolman, 75 (1998): 87100; "Constitutional Democracy: A Paradoxical Union of Contradictory Principles?". Political Theory, 29 (2001): 766-781; "Intolerance and Discrimination". International Journal of Constitutional Law, 1 (2003): 2-12; "Religious Tolerance - The Peacemaker for Cultural Rights". Philosophy, 79 (2004): 5-18.

34 Cf. RAWLS, J. Political Liberalism. New York: Columbia University Press, paperback edition with a new introduction, 1996 (especialmente a quarta lição: "The Ideal of an Overlapping Consensus", p. 133-172). 
"meta" (aim) e o da neutralidade de "efeito" ou "influência". ${ }^{35}$ No primeiro sentido, que é aquele adotado pelo liberalismo político, Habermas aponta a seletividade da leitura desconstrucionista, incapaz de examinar os passos da história constitucional moderna de implementação dos direitos, básicos sob a ótica de um processo de aprendizagem que pode ser reconstruído através de vários exemplos como aqueles fenômenos mencionados no início deste artigo - de lutas pelo reconhecimento, adotando uma interpretação falibilista da razão prática, a qual, consciente da incompletude e da corrigibilidade das reivindicações associadas ao princípio do igual tratamento das pessoas, e, portanto, da diferenciação progressiva entre o justo e o bem, nem por isso está conceptualmente obrigada a admitir a inconsistência da idéia de igualdade cívica por causa de sua realização histórica parcial, como se a falibilidade implicasse a supressão ou a relativização da verdade reivindicada. O outro sentido da neutralidade, rejeitado por Rawls, traz à tona o problema específico estudado à parte por Habermas, como veremos da exclusão de visões fundamentalistas de mundo e de grupos iliberais, mas tampouco abala o princípio da igualdade política a ponto de significar uma concessão ao desconstrucionismo, na medida em que os efeitos diferenciados das normas justificadas imparcialmente sobre a autocompreensão ética e a forma de vida de cada cidadão, enquanto indivíduo e enquanto membro de um grupo, devem ser tratados, não apenas na perspectiva da primeira pessoa que busca realizar seu projeto racional de vida, mas também na perspectiva do participante envolvido na formação da opinião e da vontade política razoável, perspectivas que não encontram solução satisfatória em termos de simbiose, devendo ser mantidas vinculadas de modo assimétrico por boas razões normativas, tais como a consideração moral pelos outros e a reciprocidade da co-legislação democrática. Nas palavras de Habermas, à guisa de conclusão da argumentação contrária à sugestão do liberalismo pósmoderno, "nem os fracassos reais em realizar a 'neutralidade de objetivo', nem os 'efeitos não-neutros' de direitos igualmente distribuídos, fornecem apoio à idéia de um 'limite para a igualdade' que seria inerente ao próprio conceito de igualdade cívica. Não há modo algum de estabelecer, apenas por análise conceptual, qualquer sofrimento inevitável do indivíduo que todo sistema de igualdade produz mediante as suas operações de exclusão e os efeitos de suas restrições" ${ }^{36}$

\footnotetext{
35 Vide a quinta lição ("The Priority of Right and Ideas of the Good"), in: Idem, Ibidem, p. 172-211. Na realidade, Rawls distingue inicialmente um sentido procedimental de neutralidade rejeitado em virtude do fato de que a base da unidade social num regime democrático-constitucional é a concepção política de justiça que constitui o foco de um consenso sobreposto das doutrinas abrangentes razoáveis, base comum que não é procedimentalmente neutra, mas formada por idéias implícitas na cultura política pública e, em seguida, a neutralidade de efeito igualmente rejeitada por ser, além de impraticável, simplesmente indesejável, pois implica que os princípios políticos tenham a mesma influência sobre todos os modos de vida permissíveis e um duplo sentido da neutralidade de objetivo não o de que as instituições políticas devam assegurar quaisquer concepções de bem afirmadas pelos cidadãos, e sim no sentido de que uma ordem política liberal não deve favorecer ou promover nenhuma doutrina abrangente particular sujeita ao desacordo razoável entre os membros da sociedade.

${ }^{36}$ HABERMAS, J. "Equal Treatment of Cultures and the Limits of Postmodern Liberalism", p. 13.
} 
No que respeita ao segundo aspecto dos direitos de grupos, Habermas sublinha a tensão entre a facticidade e a validade do sistema de direitos, cuja realização integral parece exigir a implementação de direitos culturais para os membros de grupos discriminados, a fim de corrigir efeitos assimétricos irrazoáveis das normas governadas pelo princípio da igualdade cívica. Não há interesse do autor nos casos triviais de prioridade dos direitos básicos sobre as leis ordinárias, que nada têm a ver com uma misteriosa conversão do universal ao particular, e sim nos casos em que o reconhecimento mútuo da igualdade dos cidadãos é violado na dimensão fundamental do pertencimento a uma mesma cultura política liberal, requerendo uma transformação das relações interpessoais com vistas à superação de uma inclusão incompleta e desigual dos membros da comunidade política. Eis a razão pela qual Habermas reconhece a importância de uma distinção analítica entre as dimensões da justiça social, que "concerne às relações verticais entre cidadãos de uma sociedade estratificada", e do pertencimento, que "se refere às relações horizontais entre membros da comunidade política", ambas inerentes à noção de igualdade cívica, cuja realização plena é medida, por um lado, segundo a justa distribuição de oportunidades e recursos, e, por outro lado, de acordo com o reconhecimento recíproco de direitos culturais. ${ }^{37}$ Entretanto, se é incorreta a incorporação da política do reconhecimento na política da distribuição, não é menos incorreto, aos olhos de Habermas, assimilar uma compreensível introdução de direitos coletivos como garantia de acesso de todos os indivíduos a um pano de fundo cultural sem o qual tanto a formação quanto a estabilização das identidades pessoais são impossíveis, em decorrência da insuperável dependência de cada indivíduo em face de uma rede simbólica de relações sociais e culturais ao falso modelo dos direitos suplementares que viriam corrigir a política da igualdade tornada aporética. Embora a introdução de direitos de grupos faça emergir novos conflitos, diferentes das disputas tradicionais entre indivíduos, de um lado, e entre o indivíduo e o Estado, de outro, o caso exemplar da potencial opressão interna aos grupos demonstra que a legitimidade dos direitos coletivos que asseguram o igual tratamento de grupos culturais só pode derivar da demonstração de que não violam necessariamente os direitos básicos dos membros individuais dos grupos. Nesse sentido, a rejeição habermasiana do multiculturalismo forte, que não leva

\footnotetext{
${ }^{37}$ Idem, Ibidem, p. 16. A idéia de um significado intrínseco da cultura para os indivíduos não é estranha à teoria do agir comunicativo e está fundada numa perspectiva normativa, segundo a qual a integridade moral do indivíduo não pode ser garantida sem a proteção do mundo da vida intersubjetivamente compartilhado no qual a sua identidade é formada. Contudo, a justificação de direitos culturais em termos de facilitação da igual inclusão dos cidadãos não implica juízo de valor sobre tal ou qual cultura, e menos ainda sobre todas as culturas, nem mesmo sob a forma da "presunção" tayloriana do igual valor. Daí que a aprovação de Habermas à posição de Barry, de acordo com a qual a cultura não é o tipo correto de entidade apta a funcionar como portadora de direitos, vem acompanhada de uma reprovação ao fato de que o ponto dos direitos culturais se perde quando os mesmos são incorporados ao modelo de bem-estar social, ocorrendo assim uma assimilação indevida das convicções às preferências. De fato, como observa Habermas, em nota na página indicada, o autor afirma que "a posição em relação a preferências e crenças é similar" (BARRY, B. Culture and Equality: an egalitarian critique of multiculturalism, p. 36).
} 
em conta esse requerimento e adota "uma estratégia de justificação a qual não exclui direitos coletivos que potencialmente restringem direitos básicos", ${ }^{38}$ reside no fato de que direitos não se referem diretamente a recursos culturais, e sim aos seus beneficiários, tornando imprópria a aplicação do modelo preservacionista das espécies naturais à cultura, que não é em si mesma portadora de direitos "porque não pode encontrar as condições de sua reprodução com seu próprio poder, mas depende da apropriação construtiva por intérpretes autônomos que dizem 'sim' ou 'não'." 39

Essa última observação em torno de uma apropriação reflexiva das tradições culturais faz emergir a questão da eqüidade diante das pressões adaptativas requeridas pela ordem liberal das doutrinas abrangentes que não comungam de seu credo político. Tendo rejeitado o argumento da autocontradição inerente ao conceito de igualdade cívica em virtude da realização apenas parcial da chamada neutralidade de objetivo, Habermas trata do problema das restrições diferenciadas impostas às comunidades e doutrinas tradicionais cujos valores e crenças fundamentais não se encaixam integralmente no quadro político da ordem jurídica talhada ao feitio do universalismo igualitário de uma moralidade pós-convencional, que promove a tolerância mútua como conditio sine qua non para a integração dos cidadãos numa cultura política democrática. Neste sentido, o sistema moderno de tolerância religiosa, cuja justificação está vinculada em termos conceptuais à democracia como base de legitimação de um Estado secularizado, representa um

${ }^{38}$ Ibidem, p. 20. A notar que não são poucos os casos em que a distinção feita por Kymlicka entre dois tipos de direitos de grupos legítimos de "proteções externas" e problemáticos de "restrições internas" (vide nota 8 acima) deixa de ser esclarecedora, quando os mesmos direitos coletivos servem simultaneamente a ambas as funções, como ilustra Habermas (p. 19-20) com o famoso caso da isenção coletiva da escolarização plena, que permite a ausência escolar nas últimas séries do ensino médio, obtida pela comunidade Amish do Estado americano de Wisconsin, caso também comentado exaustivamente por Barry (cf. Culture and Equality: an egalitarian critique of multiculturalism,, p. 176-193 e pp. 207-212). O problema, então, é o de estabelecer claramente a legitimidade de direitos de grupos derivados de direitos culturais dos membros individuais dos grupos, frente à qual a posição de Kymlicka, na minha opinião, permanece ambígua, como no exemplo da prática de clitoridectomia em determinadas culturas, ou ainda, em se tratando de impacto externo ao grupo, no da sentença de morte decretada pelo fanatismo religioso aos infiéis recalcitrantes (cf., p. ex.: KYMLICKA, W. "The Theory and Practice of Immigrant Multiculturalism", in: Politics in the vernacular: nationalism, multiculturalism and citizenship, p. 152-176).

39 Ibid., p. 22. Tal modelo já havia sido identificado pelo autor na política do reconhecimento de Taylor, cuja ética do bem fundada em bases metafísicas é solidária de uma política da sobrevivência cultural, rejeitada por Habermas em razão do fato de que "a perspectiva ecológica da conservação das espécies não pode ser transferida às culturas" ("Struggles for Recognition in the Democratic Constitutional State", in: The inclusion of the other: studies in political theory, p. 222). Numa menção aprobatória da reflexão habermasiana, Barry contrasta o movimento de "renovação cultural" de um tradicionalismo autoconsciente com o conservadorismo da posição multiculturalista forte (cf. BARRY, B. Culture and Equality: an egalitarian critique of multiculturalism, op. cit., p. 259), destacando justamente o argumento em prol do valor incondicional da diversidade pela analogia com o valor da biodiversidade, como na sentença de Bhikhu Parekh: "Se estamos preparados para preservar espécies botânicas e zoológicas raras, mesmo quando não vemos na atualidade seu valor, não faz sentido destruir modos de vida que não causam danos óbvios e identificáveis a si mesmos ou a outros" (apud Idem, ibidem, p. 134; a ironia de Barry, ao comentar essa passagem, é demolidora: "Há tantas coisas erradas com isso que é difícil saber por onde começar"). 
precursor dos direitos culturais atualmente reivindicados, uma vez que "a demanda cognitiva feita pelo Estado liberal às comunidades religiosas é exatamente a mesma para as comunidades seculares 'fortes' (tais como minorias nacionais ou étnicas, populações imigrantes ou indígenas, descendentes de escravos, etc.). As tradições por eles prosseguidas abrem 'perspectivas de mundo' que, como as imagens religiosas de mundo, podem entrar em conflito umas com as outras. Por conseguinte, há uma igual expectativa de que grupos culturais adaptem seu ethos interno aos padrões igualitários da comunidade ao redor" ${ }^{40}$ Contudo, embora a exigência seja idêntica, os recursos conceptuais não são os mesmos, especialmente quando a cultura em questão está entrelaçada com uma visão religiosa de mundo, para a qual o requisito institucional da separação entre a religião e a política não pode ser transformado numa carga adicional indevida que exigiria uma espécie de partição da identidade num aspecto público e noutro privado, obrigando cada indivíduo, na condição de membro de uma comunidade política, a expressar e a justificar suas convicções e crenças apenas numa linguagem secularizada. $^{41}$ Tal assimetria impõe custos desigualmente distribuídos entre os cidadãos, em conseqüência dos efeitos não-neutros da tolerância, razão pela qual, no entender de Habermas, a ética da cidadania, que se define pelas condições simétricas de participação numa prática comum de autodeterminação democrática, exige, por seu turno, atitudes epistêmicas, de acordo com as quais as dissonâncias cognitivas sejam tratadas como desacordos razoáveis entre todas as partes engajadas em processos de aprendizagem complementares, de tal modo que, por exemplo, cidadãos seculares assumam as pressões adaptativas não menos custosas de habitarem um mundo pós-secular, ${ }^{42}$ e não apenas pós-metafísico.

HABERMAS, J. "Religious Tolerance - The Peacemaker for Cultural Rights", p. 17.

1 Trata-se aqui de um limite à estratégia de tradutibilidade defendida por Rawls em seu conceito de razão pública, o qual de modo algum impede a introdução de razões morais abrangentes (seculares ou religiosas) na arena política, mas impõe a cláusula restritiva que consiste em traduzir as pretensões morais amplas para a linguagem do político, em vez de apresentar "razões dadas unicamente por doutrinas abrangentes" (RAWLS, J. The Law of Peoples; with "The idea of public reason revisited', p. 152; grifo meu).

42 Sobre o tema, cf. HABERMAS, J. "Fé e saber", in: O Futuro da Natureza Humana. São Paulo: Martins Fontes, 2004, p. 135-154. Salvo engano meu, a questão do reconhecimento serve também para assinalar uma mudança de posição acerca da complexa relação entre religião e modernidade no pensamento habermasiano, ao menos a visão predominante até ao final da década de oitenta, num sentido não completamente estranho ao que apresentei na obra Religião e Modernidade em Habermas (São Paulo: Loyola, 1996). Infelizmente, os limites do presente artigo não permitem o aprofundamento desse aspecto tão atual quanto relevante no campo da filosofia política. 